ISPEC Tarım Bilimleri Dergisi

$2020: 4(1)$

(C) Telif hakk ISPEC'e aittir

Arastırma Makalesi

\section{*Kutalmış TURHAL}

Orcid No: 0000-0002-5347-8513

**Ahmet Tuna CÖMERT

Orcid No: 0000-0003-0939-0220

*Bilecik Şeyh Edebali Üniversitesi

Ziraat ve Doğa Bilimleri Fakültesi

Biyosistem Mühendisliği Bölümü

(Sorumlu yazar)

kutalmis.turhal@bilecik.edu.tr

** Bilecik Şeyh Edebali Üniversitesi

Ziraat ve Doğa Bilimleri Fakültesi

Biyosistem Mühendisliği Bölümü

ahmet.comert@bilecik.edu.tr

DOI

https://doi.org/10.46291/ISPECJASv ol4iss1pp42-53

Geliş Tarihi: 18/01/2020

Kabul Tarihi: 27/02/2020

\section{Anahtar Kelimeler \\ RAM pompasi, ziraat, sulama}

Keywords

RAM pump, agriculture, irrigation

\section{www.ispecjournal.com}

\section{Ram Pompasının Basma Hattındaki Su Debisinin Artırılmasına Yönelik Bir Çalışma}

\section{Özet}

Tarımda sulama, zirai ürün fiyatını artışına neden olan girdi maliyetinden biridir. Sulamada kullanılan pompa sadece ürün maliyetini arttırmasının yanında kullanılan fosil yakıtlar nedeniyle çevre kirliliğine de sebep olur. Birçok ülkede sulamada uygulaması görünen RAM pompası suyun herhangi bir yükseklikten pompaya düşmesi ilkesine göre çalışır. Bir su pompası olan RAM pompa mekanizmasına düşen suyun en az onda birini su düşme yüksekliğinin on katına kadar basabilir ve bu işlemi suyun kendi özgül ağırlı̆̆ 1 ve kinetik enerjisinden yararlanarak yapmaktadır. Yani suyu terfi ettirmek için herhangi bir fosil yakıt ve/veya elektrik enerjisi sarf etmemektedir. Böylece bu pompa ile terfi ettirilen su yüksek bir depoda biriktirilebilir istendiği zaman tarım alanları cazibe ve benzeri yöntemler ile sulanabilir. Bu çalışma ile RAM pompası geliştirilerek, basma debisi \%16-\%20 oranında artırılmış, pompa imalat maliyeti \%50 düşürülmüştür. Böylece geliştirilmiş bu RAM pompa ile herhangi bir enerji kullanmadan suyun bulunduğu yerden daha yüksek yerdeki tarım alanlarına daha fazla suyun daha düşük imalat maliyetiyle iletilmesi sağlanmıştır.

\section{A Study to Increase The Water Flow in The discharge Line of Ram Pump}

\section{Abstract}

Irrigation in agriculture is one of the major input costs that increase the price of agricultural products. The pump used in irrigation not only increases the product cost but also causes environmental pollution due to the fossil fuels used. In many countries, the RAM pump used for irrigation works on the principle that water from any height falls into the pump. RAM pump, a water pump, can pump at least one-tenth of the water up to 10 times the water height and it does this by making use of its specific gravity and kinetic energy. In other words, it is not used any fossil fuel and / or electrical energy to pump water. The water promoted by this pump can be stored in a high tank and so, agricultural areas can be irrigated by attraction and similar methods. With this study, the RAM pump was developed, the discharge flow rate was increased by $20 \%$ and the pump manufacturing cost was reduced by $50 \%$. Thus, with this improved RAM pump, it was ensured that the water was transferred to the higher place without using any energy and this was done at a lower cost. 


\section{GíRIŞ}

RAM pompası iki yüzyıldan beri kullanılan eski bir pompadır. Benzinli motorların icadı ve tarımda elektrik kullanılmadan önceki zamanlarda ram pompası birçok yerde akarsulardan ve komşu yamaçlardaki kaynaklardan suyun daha yüksekteki noktalara iletilmesinde kullanılmıştır. Günümüzde kullanılan RAM pompasının daha verimli ve sorunsuz çalışması, eskiden beri üzerinde birçok değişikliğe uğratılmasıyla sağlanmıştır. İnsanlık önce enerji kaynağı olarak fosil yakıtları yerden çıkarmak, işlemek ve kullanmak için çalışmıştır. Sonra elektrik üretmek için yerden çıkardığ fosil yakıt ve yeryüzünde bulunan diğer doğal kaynakları da kullanan termik, nükleer, doğalgaz, termal su ve hidroelektrik santralleri kurmuştur. $\mathrm{Bu}$ süreçte doğanın önce dengesi bozulmuş sonrada oluşan atıklarla Dünyayı çevre kirliliği gibi büyüyen bir sorunla karşı karşıya bırakmıştır. Sonuçta pompaları çalıştırmak için kullandığımız fosil ve elektrik enerji kaynakları çevre kirliliğine neden olmaktadır. Ayrıca klasik pompalar güçlü ama bakımı pahalıdır. Çünkü çelik, döküm, tunç ve pirinç malzemeler kullanılarak imal edilmektedir. RAM pompa yapisal olarak iki hareketli parçadan oluşan basit bir alettir. Bunlar basma ve iletme valfleridir. Ayrica pompaya suyun akışında meydana gelen aralıkları yok etmek ve sürekli akan su haline getirmek için hava hücresi (hava tankı) eklenmiştir. Pompanın çalışması aralıklı olarak açılıp kapanan valflerle olmaktadır. Basma valf kapanmasıyla yüksek basınç yaratır ve su boru boyunca ilerler. Böylece hava hücresinde oluşan yüksek basınç ile pompaya gelen suyun çıkışı sürekli olur (Mohammed, 2007). RAM pompası basit, bakımı kolay ve ucuzdur. Çalışmasında sadece suya ihtiyaç duyar. Çalışması için suyun belirli bir yükseklikten pompaya verilmesi yeterlidir. Suyun miktarı ve gücü önemli değildir. Önemli olan su kaynağının RAM pompasından daha yüksek bir yerde olmasıdır. RAM pompaya bir düşü ile gelen su önce pompayı çalıştıran hareketi sağlar, sonra gelen suyun bir kısmı su kaynağından daha yüksek bir yere basılır. Aynı anda gelen suyun önemli bir kısmı da kalan su olarak kaynağa geri birakılır. RAM pompasının çalışabilmesi için düşü yüksekliğinin minimum $1 \mathrm{~m}$ olması yeterlidir. $\mathrm{Bu}$ yükseklik artarsa, suyun kaynaktan daha yüksek bir yere iletilmesi, ya da belirli bir yüksekliğe iletilen suyun debisinde artış sağlanmış olur. Pompa, kaynaktan gelen suyun en az onda birini ve 
kaynaktan pompaya düşü mesafesinin 10 katına kadar yukarıya basılabilir. Burada en büyük sorun iletilen suyun iletim borusunun sonuna basıncı zayıf olarak ulaşması ve iletilecek olan yükseklik ve mesafe arttıkça su debisinin azalmasıdır. İletilen su debisinin arttırılması ise pompa içindeki sürtünme kayıplarının azaltılması pompa etkinlik derecesi katsayısının arttırılması ile mümkündür. Tasarladığımız pompa ile piyasada bulunan RAM pompalarına göre etkinlik derecesi katsayısı arttırılmıştır. RAM pompası ile iletilen su neredeyse sıfir su basıncı değerinde iletim hattının sonuna ulaştığı için, doğruca basınçlı su ile sulamada kullanıma uygun değildir. $\mathrm{Bu}$ pompa ile su, sulanacak alandan daha yüksek bir rakıma depolanmak için basılır. Yani bu pompanın kullanıldığı yerde sulanacak alan, depolanan sudan daha düşük rakımda olmalıdır. Çünkü depodan alçak rakımdaki yerler cazibeyle sulanırken sulama suyuna yükseklik farkı kadar basınç kazandırılmış olur. Calvert (1967)'e göre iletim borusunun boyutunun belirli bir sınır değeri vardır. Hidrolik pompasının performansının basınç oranı ve sürtünme katsayısı ile ilişkili olduğunu boyutlu analiz tekniği uygulanarak bulmuştur. İlgili parametreler basınç oranı, sürtünme katsayısı ve Froude, Reynolds ve Mach katsayılarıdır. Pompanın performansında Reynolds sayısının Mach sayısına göre etkisinin fazla olduğu ve verimliliğin basınca bağlı arttırılmasında Froude sayısının önemli olduğunu ispatlanmıştır. Otomatik bir hidrolik pompanın çalışma anında oluşan sürtünme kayıplarının pompanın hangi kısımlarında oluştuğu bellidir. $\mathrm{Bu}$ kayıplar, basma valfindeki basınç kaybı, basma valfinin sürtünme katsayısı, boru içindeki basınç kaybı ve yavaşlama periyodu boyunca oluşan basınç kaybıdır (Krol, 1951). Köy kullanımı için hidrolik pompa ABD'de VITA tarafindan geliştirilmiştir. Pompa sadece küçük bir su temini için basma valfi yaylı mekanizmasından tasarlanmış iken, iletim valfi basit kapak valfi şeklinde kullanılmıştır. Tasarımla hidrolik pompanın genel bir tanımı yapılmış ve problemlerin çoğu çözülmüştür (Molyneux, 1960). Calvert (1967), Krol (1951) ve Molyneux (1960) ispatları doğrultusunda tasarladığımız pompanın emme ve basma valfları arasındaki mesafe düşey doğrultuda imal edilmiştir. Ayrıca düşey doğrultuda imalat şekli ile enerji kayıplarına neden olan mesafe azaltılmıştır.

$\mathrm{Bu}$ çalışmada düşey doğrultuda imalat şekli ile kaynaktaki suyun pompaya düşü mesafesinin (F) 6 katına kadar yukarıya 
basıldığında iletilen su (L) gelen suyun onda biri kadar olması sağlanmıştır (Şekil 2).

\section{MATERYAL ve YÖNTEM}

$\mathrm{Bu}$ proje 2014-2015 yılında arasındaki Bilecik Şeyh Edebali Üniversitesi deneme sahasında yürütülmüştür. Pompa yapımında kullanılan malzemeler aşağıdaki tabloda belirtilmiştir.

Çizelge 1. Hidrolik RAM pompa parçaları

\begin{tabular}{|c|c|c|}
\hline \multicolumn{3}{|l|}{ RAM Pompası Parçaları } \\
\hline 2"' plastik pompa (10 metre) & 2" T boru & Musluk \\
\hline 2" Basma valfi & 2'' sipo nipel & İletim deposu \\
\hline 1, '́letim Valfi & 2" $\mathrm{x}$ 4" geçiş borusu & $120 \mathrm{~cm} \times 4$ "' basınç tank1 \\
\hline 1', nipel & Tek yönlü valf & 1 " iletim hortumu $(100 \mathrm{~m})$ \\
\hline 2' nipel (3 parça) & & Yaylı düșey valf \\
\hline 4', nipel & & Manometre \\
\hline
\end{tabular}

\section{RAM Pompası Çalışma Sistemi}

(a) Kaynaktan gelen su tahrik borusundan RAM pompası gövdesine akar, onu doldurur ve çıkış valfinden (B) çıkmaya başlar. Çek valf (C) kapalı konumda kalır. Bu başlangıç noktasında, depoda (D) basınç yoktur ve çıkış borusundan (E) su depoya varış yerine su gönderilmez (Şekil 1).

(b) (B)'ye takılı yay mekanizması suyun akış kuvvetini yenerek (B) valfini kapatır.
Bu kapanma ile bir şok oluşur. Bu şok (C) valfinin açılmasını sağlar ve hava tankına suyun girmesi sağlanır (Şekil 2).

(c) $\mathrm{Bu}$ aşamada hem (B) hem de (C) valfleri kapalıdır. Tanktaki hava, suyun tanka girmesiyle sıkışmış ve tank içindeki basınç yükselmiştir. Basınç eşitleninceye kadar su (E) borusundan kesintisiz olarak çıkacaktır. Basınç eşitlenince sistem yeniden başlar (Şekil 3)
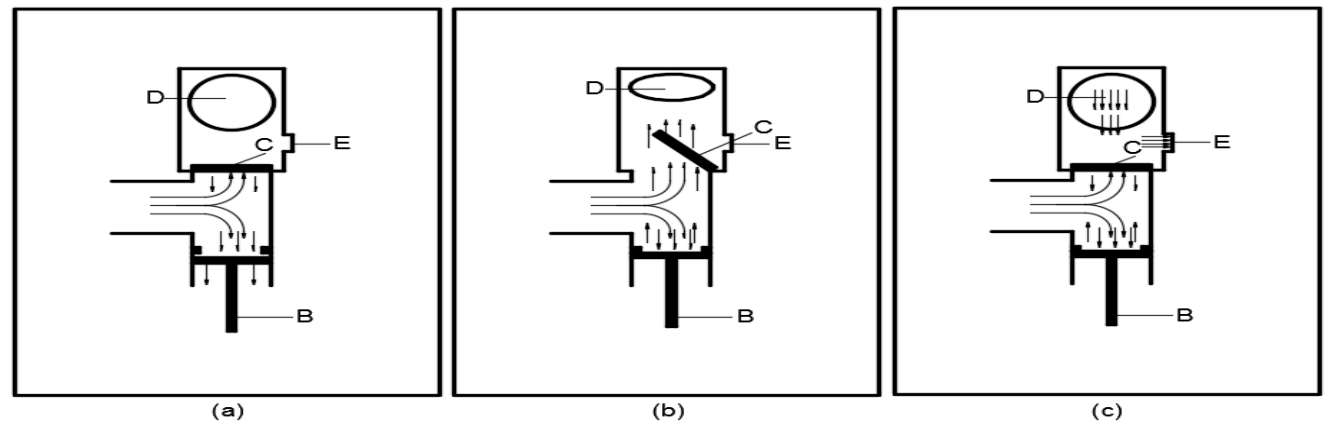

Şekil 1. Hidrolik RAM pompa çalışma sistemi ( $A=$ Giriş borusu,

$\mathrm{B}=$ Pompa yaylı düşey valf, $\mathrm{C}=$ Yatay valf, $\mathrm{D}=$ Hava tankında sıkışan hava ve $\mathrm{E}=\mathrm{Bas} ı$ ç borusu) 


\section{Pompa Yapımında Yararlanılan \\ Formüller}

Pompaya gelen suyun debisi şu şekilde hesaplanır:

$$
Q=\frac{\pi r^{2} L n}{10}
$$

Burada, $Q$, gelen su debisi (lt/dk), $r$, giriş borusu yarıçapı $(\mathrm{cm}), L$, giriş borusu uzunluğu (m), $n=$ devir hızı (1/dk). Ayrıca, suyun pompaya iletilen borudaki akışkan akış hızı,

$$
V_{d}=\frac{Q}{10 A_{d}}
$$

Burada, $V_{d}$, akışkan akış hızı $(\mathrm{m} / \mathrm{s})$ ve $A_{d}$, boru yüzeyi $\left(\mathrm{dm}^{2}\right)$

Reynolds sayısının (Re) belirlenmesi akış türünü belirlemek için (bu laminer veya türbülanslı olsun) önemlidir. Formül, $\operatorname{Re}=\frac{V D}{\mu}$ şeklindedir. (Sümer, 2015)

Burada, $V$, akışkan akış hızı $(\mathrm{m} / \mathrm{s}), D$, boru çap1 (m) ve $\mu$, kinematik viskozitedir.

$f$ değeri borunun göreceli pürüzlülügüünü (yüzey kusur büyüklüğünün borunun iç çapına oranı) etkilemektedir (Nikuradse ve ark. 2010).

$$
f=\frac{0,316}{\operatorname{Re}^{1 / 4}}
$$

BLASIUUS bağıntısı

(Sümer, 2015)

Burada, $f=$ borunun sürtünme katsayısı ve Re, Reynolds sayısıdır.
Darcy-Wersbach formülü, borulardaki ve borulardaki akışkan akışındaki yük kaybının değerlendirilmesinin temelidir ve aşağıdaki formülle açıklanır.

$J=f \frac{L}{D} \frac{V^{2}}{2 g} \quad$ (Sümer, 2015)

Burada $J$, yük kaybı (m), $L$, birim boru boyu (m), $V$, ortalama akım hızı $(\mathrm{m} / \mathrm{sn}), D$, boru çapı $(\mathrm{m}), g$, yerçekimi ivmesi $\left(\mathrm{m} / \mathrm{sn}^{2}\right)$

Yük kaybı, boru uzunluğu veya su hızı karesi ile doğru orantılıdır.

Yük kaybındaki artış, kaynaktan gelen su borusunun uzunluğuna, gelen suyun yüksekliğine ve suyun hızına bağlıdır. Borunun yüksekliği ve uzunluğu sabit olduğundan, hız artarsa yük kaybı da artacaktır. Pompadaki su akışı, yük kaybı arttıkça ve pompaya gelen su daha kısa sürede pompadan geçerken artacaktır. Böylece, daha fazla su itilecektir.

Mevcut RAM pompalarında, pompaya gelen su yatay olarak dolaşır ve pompadan çıkar. RAM pompamızda ise su yatay değil dikey olarak hareket ediyor. Böylece su, pompayı daha hızlı terk eder ve kaynaktan daha fazla su alır.

Özetle, belirtilen yüksekliğe daha fazla su yükseltilebilir.

Pompa akış hızı için matematiksel bir ilişki vardır. Tahrik borusu boyunca akış hızı, disk borusu yoluyla kaynaktan dikey 
düşme ve kullanım alanına pompa dikey yükseklik kaldırmaya dayanmaktadır. $\mathrm{Bu}$ değişkenler, pompalama hızını hesaplamak için kullanılır.

İletilen su Şekil 2‘de gösterilmiştir.

1- Basma hattındaki düşey mesafe $(F)$ arttıkça,

2- İletilen yükseklik $(L)$ azaldıkça

3- $L / F$ oranı 1'e yaklaştıkça iletilen su artmaktadır.

İletilen su miktarı aşağıdaki formüle göre hesaplanmaktadır.

$$
Q=\frac{1,44 E S}{L / F}
$$

Burada:

- $Q$, iletilen su miktarı ( $\left.\mathrm{m}^{3} / \mathrm{day}\right)$

- 1440 , bir gün içindeki toplam saat x bir saat içindeki toplam dakika (24h x 60dak)

- $E$, hidrolik RAM pompası etkinlik katsayısı 0,6 $(\mathrm{Bu}$ oran arttıkça iletilen su miktarında artış olmaktadır.)

- $S$, dakikada makineye verilen su debisi $(1 / \min )$

- $F$, pompaya gelen suyun pompa ile arasındaki düşey yükseklik (m)

- $L$, çıkış noktası ile pompa arasındaki düşey mesafesi (m)

\section{Deney Sonuçlart}

Dünyada kullanılan RAM pompaların birbirleri ile hemen hemen aynı olduğu tespit edilmiştir. Sadece ufak değişiklikler içermektedirler. Bu çalışmada Dünyada üretilen RAM pompalardan bir tanesi örnek alınmıştır (Anonim, 2009). Daha sonra bunun üzerinde çalışılarak düşey yay sistemi ve gövdede farklılıklar yapılmış eskisinin yanında ikinci yeni bir tasarım yapılmıştır. İki pompa karşılaştırılmıştır. Yeni tasarlanan pompa eskiye göre yaklaşık $\% 10$ daha fazla suyu iletebildiği ve öncekine göre \%15 daha az suyla bunu yapabildiği görülmüştür. Ayrıca her yerde bulunabilecek parçalarla maliyet olarak ta neredeyse $\% 50$ düşük bir oranda imal edilmiştir. Pompa hem kullanım hem bakım hem de yapımında ve çalışmasında önemli farklar elde edilmiştir. Yeni pompa eskiye göre daha az suyla daha rahat çalıştığı da tespit edilmiştir. Yeni ürettiğimiz pompanın dünyada üretilen RAM pompalara göre yukarıda sayılan farklılıkları içermektedir. Daha sonra pompanın faydalı model patentine başvurulması düşünülmektedir. Çalışma özgün bir çalışma olmuştur.

Pompa meyilli olan akan suda (nehir, dere yatakları vb.), kanallarda, barajlarda kullanılabilmektedir. Burada önemli olan nokta, gelen suyun bulunduğu seviyeden daha düşük seviyeye düşürülebilmesidir. Yani su belli bir yükseklikten düşürülerek hız kazandırılmalıdır. Pompanın çalışması gelen su ile olmaktadır. Gelen suyun az 
miktarı (bu oran iletilecek yüksekliğe göre değişmektedir) istenilen yüksekliğe çıkarılırken kalan kısım pompanın bulunduğu su kaynağında kalmaktadır. Eğer kalan su kaynağına geri konamıyorsa bu pompa kullanışlı olmaktan çıkmaktadır.

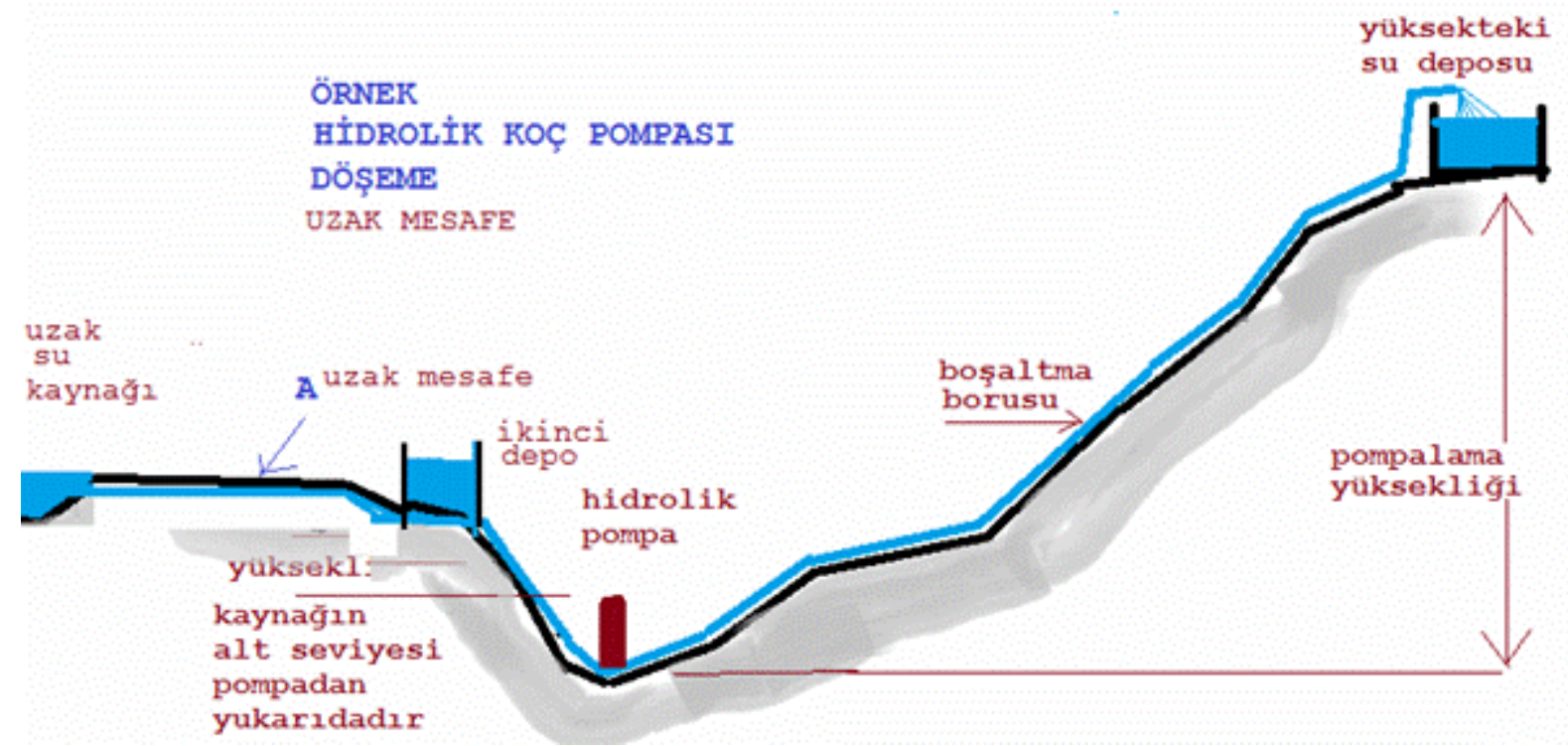

Şekil 2. RAM pompa çalışma sistemi ( $\mathrm{F}=$ Kaynak alt seviyesinden pompaya kadar olan düşey mesafe, $\mathrm{L}=$ Depolanan su alanından pompaya kadar olan düşey mesafe)

İkinci aşamada yeni tasarlanan pompa ile dünyada kullanılan pompa aynı şartlarda denenmiş sonuçlar tabloda belirtilmiştir. Her deneme 5 defa tekrar edilerek denenmiştir. Sonuçların ortalaması alınmıștır (Çizelge 2, Çizelge 3). Tasarlanan pompanın teknik resim çizimleri Şekil 3 ve 4, perspektif görünüşü şekil 5'de gösterilmiş̧ir.

Çizelge 2. Standart RAM pompa sonuçları

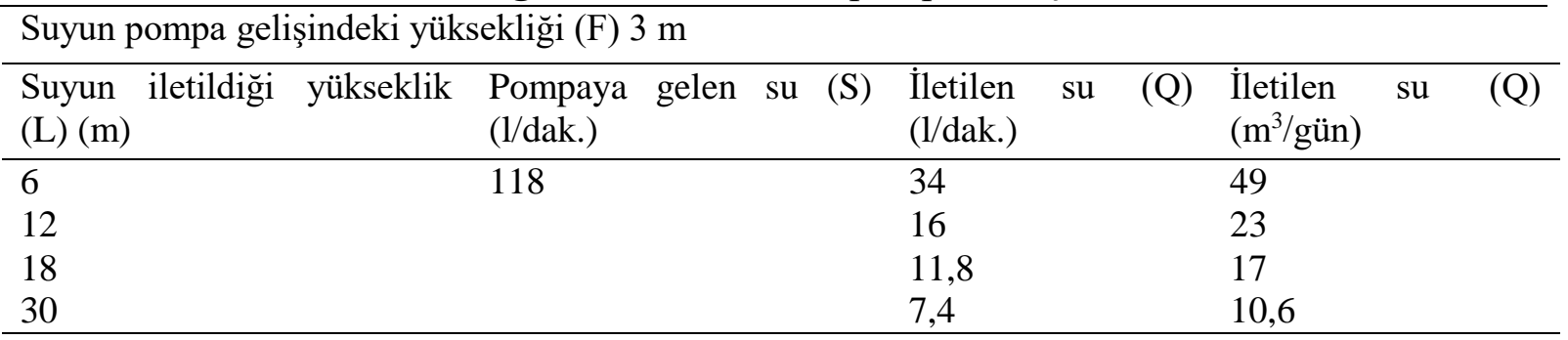


Çizelge 3. Tasarlanan RAM pompa sonuçları

\begin{tabular}{|c|c|c|c|}
\hline \multicolumn{4}{|c|}{ Suyun pompa gelişindeki yüksekliği (F) $3 \mathrm{~m}$} \\
\hline $\begin{array}{l}\text { Suyun iletildiği yükseklik } \\
\text { (L) (m) }\end{array}$ & $\begin{array}{l}\text { Pompaya gelen su (S) } \\
\text { (1/dak.) }\end{array}$ & $\begin{array}{l}\text { İletilen } \\
\text { (l/dak.) }\end{array}$ & $\begin{array}{l}\text { İletilen su } \\
\left(\mathrm{m}^{3} / \text { gün }\right)\end{array}$ \\
\hline 6 & 107 & 37 & 53 \\
\hline 12 & & 17 & 25 \\
\hline 18 & & 12,5 & 18 \\
\hline 30 & & 7,8 & 11,2 \\
\hline
\end{tabular}

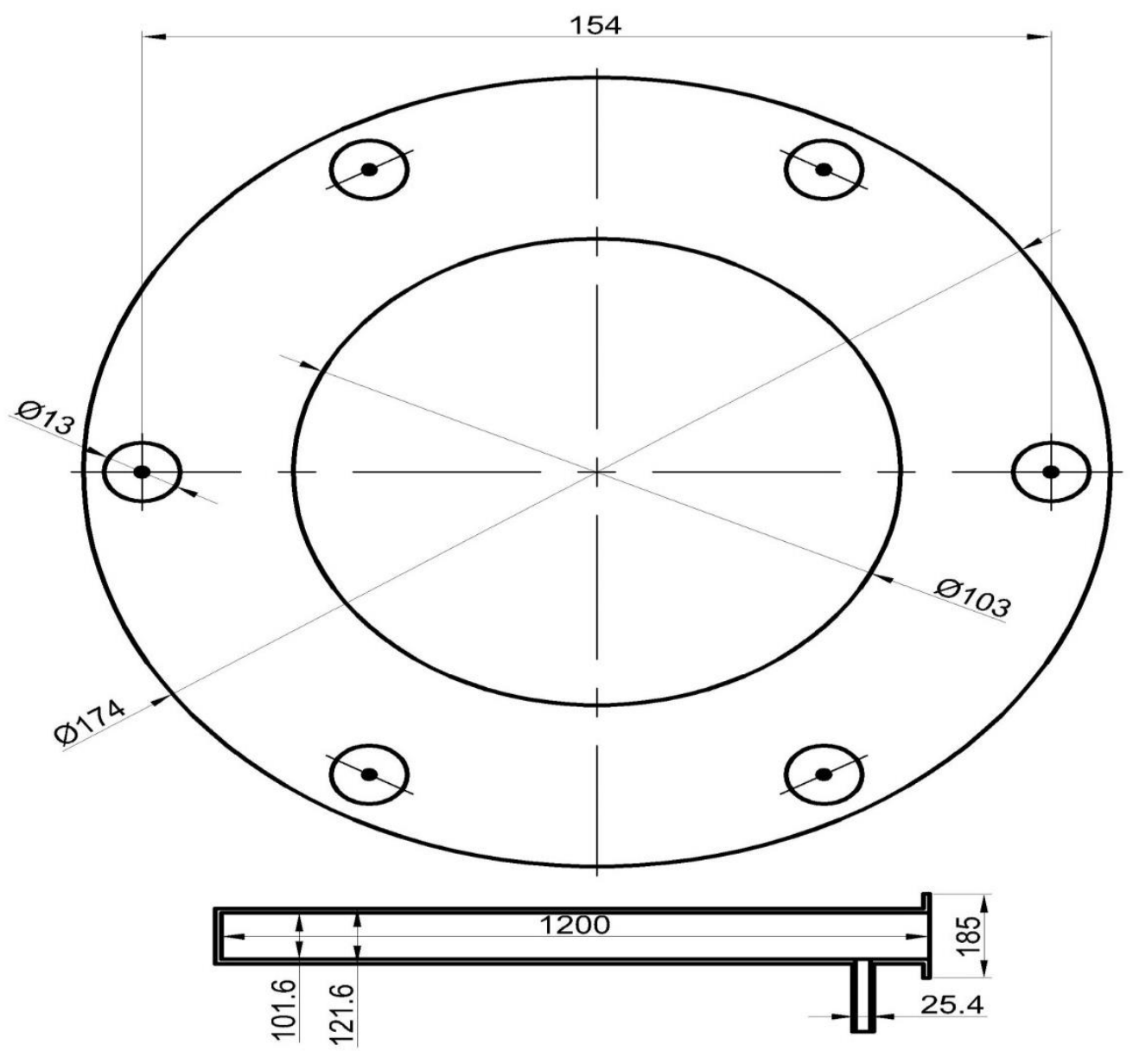

\begin{tabular}{|l|l|l|r|}
\hline Birim & Ad ve Soyad & Parça Adı & Ölçek \\
\hline Bilecik Ş. E. Üni. & Kutalmış Turhal & conta - Tüp & $1 / 1-1 / 10$ \\
\hline
\end{tabular}

Şekil 3. RAM pompa parçaları 
ISPEC Tarım Bilimleri Dergisi

$2020: 4(1)$

(C) Telif hakk ISPEC'e aittir

Arasturma Makalesi
E-ISSN:2717-7238

SPEEC

www.ispecjournal.com
ISPEC Journal of Agr. Sciences

2020:4(1)

Copyright (C) ISPEC

$\underline{\text { Research Article }}$
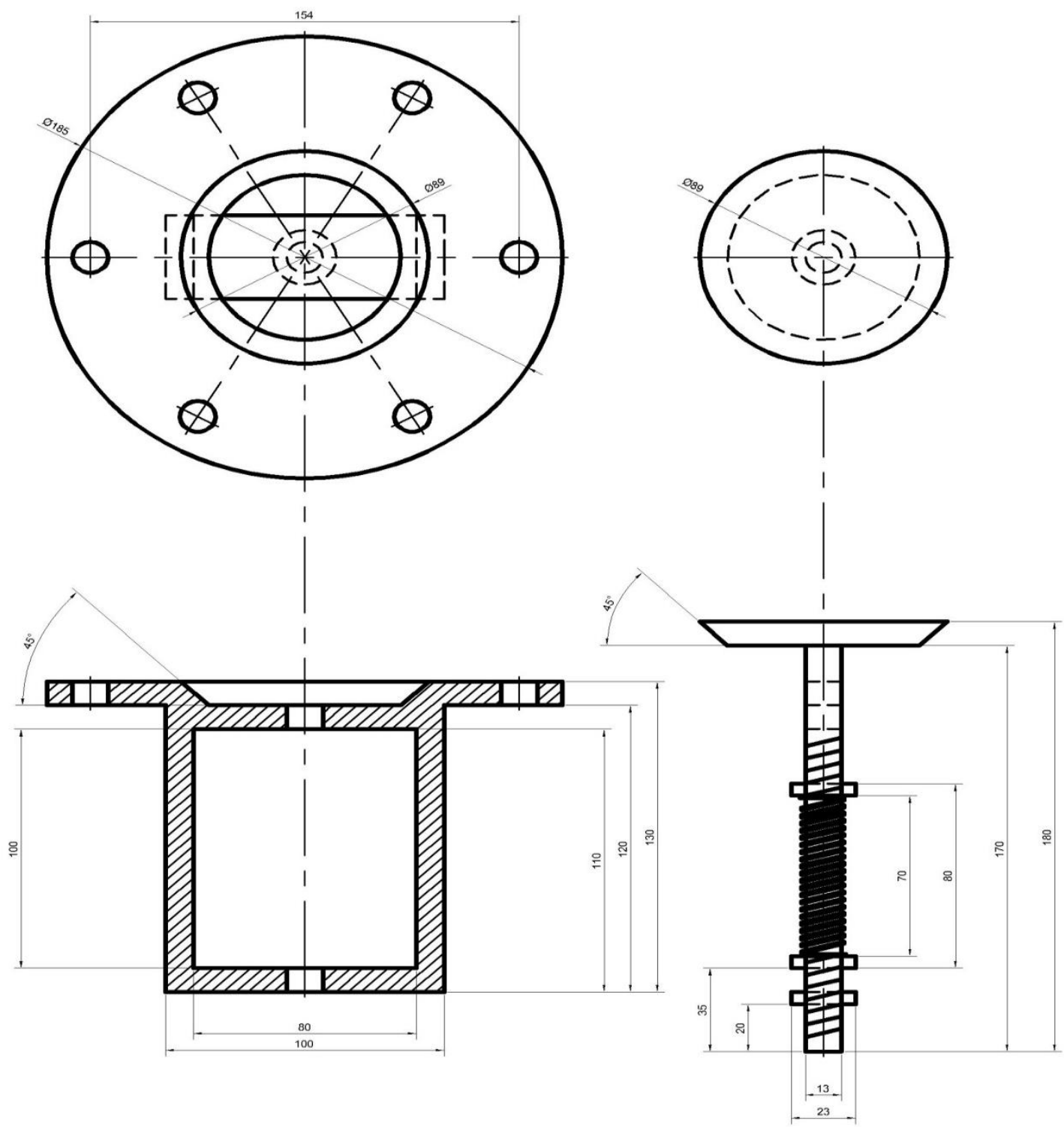

\begin{tabular}{|l|l|l|l|}
\hline Birim & Ad ve Soyad & Parça Adı & Ölçek \\
\hline Bilecik Ş. E. Üni. & Kutalmış Turhal & Düşey valf & $1 / 2$ \\
\hline
\end{tabular}

Şekil 4. RAM pompa düşey valf teknik resim çizimi 
ISPEC Tarım Bilimleri Dergisi $2020: 4(1)$

(C) Telif hakk ISPEC'e aittir Arasturma Makalesi
E-ISSN:2717-7238

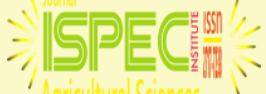

www.ispecjournal.com
ISPEC Journal of Agr. Sciences 2020:4(1) Copyright (C) ISPEC

$\underline{\text { Research Article }}$

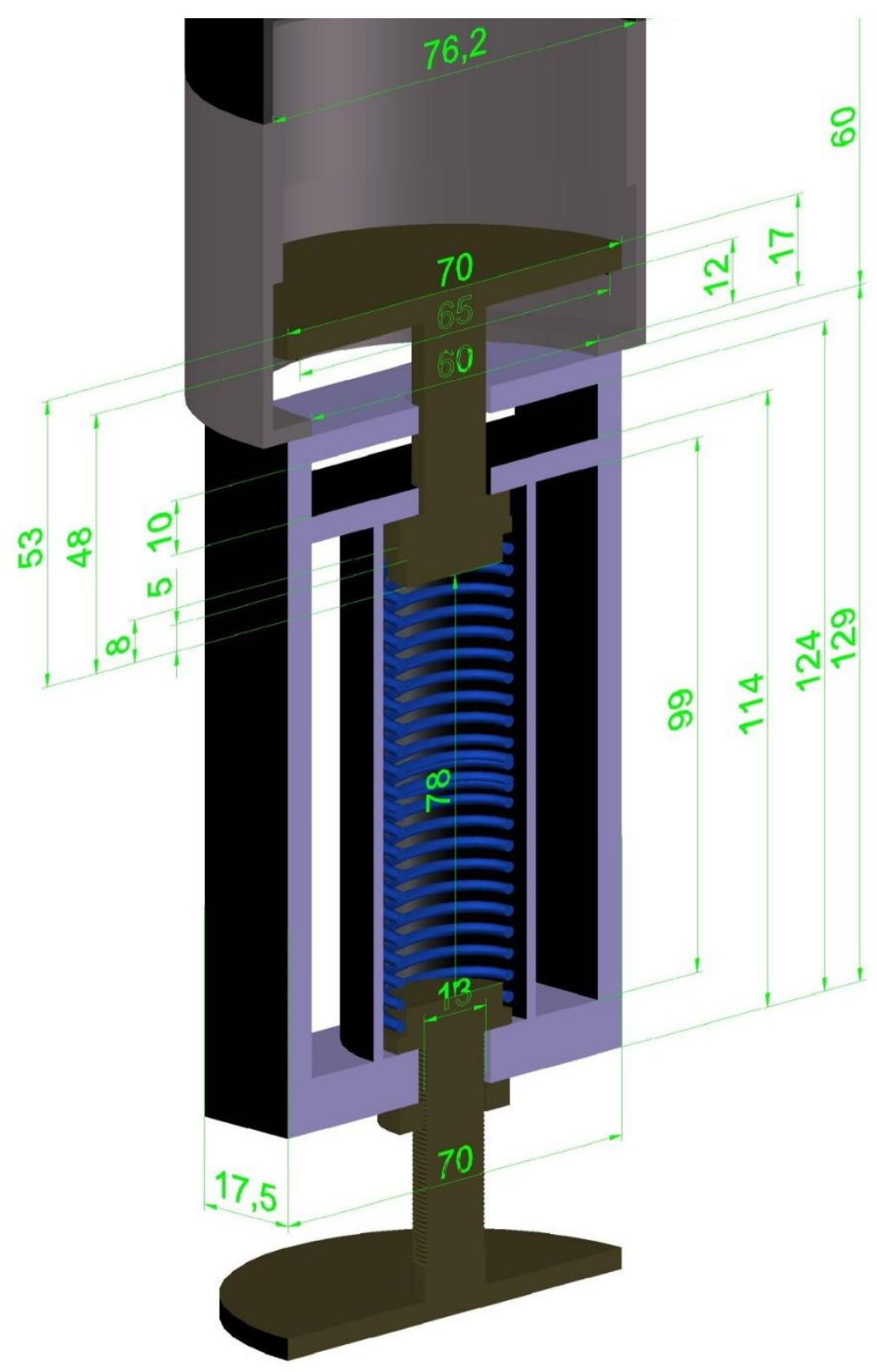

Şekil 5. RAM pompa düşey valf perspektif görünüşü 


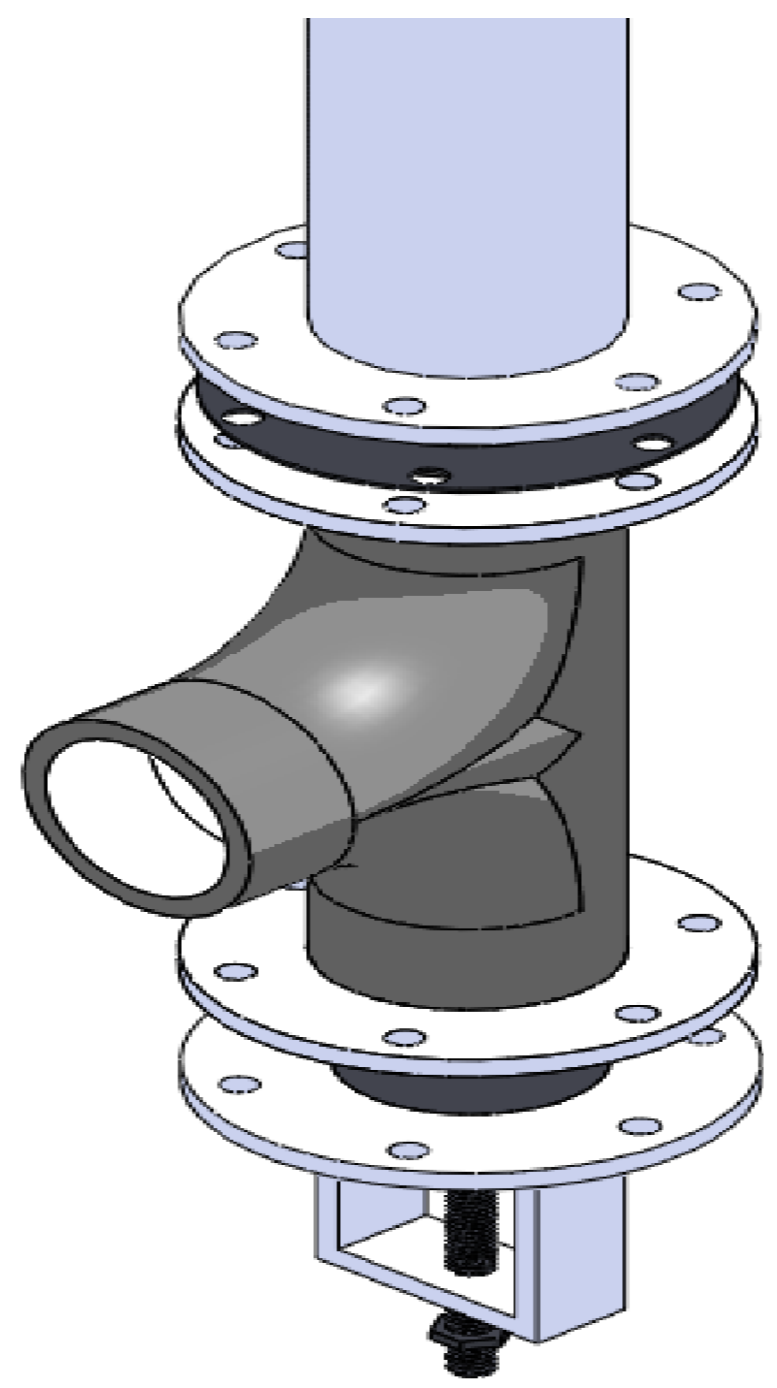

Şekil 6. RAM pompa genel görünüşü.

\section{SONUÇ ve TARTIŞMA}

Bilecik Şeyh Edebali Üniversitesinde tasarlanan yeni model pompa, dünyada kullanılan RAM pompalara göre birçok yönden avantajlı bulunmuştur. $\mathrm{Bu}$ avantajlar;

1- Düşük Maliyet

2- Montaj kolaylığı
3- Çalışma esnasında daha düzgün ve rahat çalışma

4- Atılan suyun kolay bir şekilde toplanabilmesi (Kaynağa iletmek daha az masraflı olmaktadır.)

5- Daha az su debisiyle pompadan yükseğe daha fazla su biriktirilmesidir.

Standart pompalarda; 
Pompaya gelen su 118 lt/dak.

İletilen su;

3 metreden 6 metreye $\quad 34 \quad 1 \mathrm{t} /$ dak.

3 metreden 12 metreye $16 \quad \mathrm{lt} / \mathrm{dak}$.

3 metreden 18 metreye $\quad 11,8 \quad \mathrm{lt} / \mathrm{dak}$.

3 metreden 30 metreye $\quad 7,4 \quad 1 t / d a k$.

Tasarlanan sistemde;

Pompaya gelen su 107 lt/dak.

3 metreden 6 metreye $\quad 37$

3 metreden 12 metreye $17 \quad \mathrm{lt} / \mathrm{dak}$.

3 metreden 18 metreye $\quad 12,5 \quad \mathrm{lt} / \mathrm{dak}$.

3 metreden 30 metreye $\quad 7,8 \quad 1 \mathrm{t} / \mathrm{dak}$.

Çizelge 2 ve Çizelge 3'e bakıldığında dünyadaki örnekle tasarlanan sistem arasında iletimdeki su arttırılmıştır.

Tasarlanan sistem standart pompalara göre 6 metreden iletilen sudan günde $4 \mathrm{~m}^{3} /$ gün, 12 metre yükseklikten $2 \mathrm{~m}^{3} /$ gün, 18 metre yükseklikten $1 \mathrm{~m}^{3} /$ gün, 30 metre yükseklikten $0,6 \mathrm{~m}^{3} /$ gün daha fazla suyu biriktirilebilme şansı vermektedir. 3 ayda ise yaklaşık 6 metrede $360 \mathrm{~m}^{3}, 12$ metrede $180 \mathrm{~m}^{3}, 18$ metrede $90 \mathrm{~m}^{3}, 30$ metrede 45 $\mathrm{m}^{3}$ 'lük daha fazla su biriktirilebilecektir.
Dünyadaki RAM pompalarda verimlilik randımanı katsayısı (E) 0,6 iken tasarlanan sistemde bu katsayı 0,7'ye çıkmıştır.

\section{KAYNAKÇA}

Sümer, M., Ünsal, İ., Bayazıt, M. 2015. Hidrolik, Birsen Yayınevi, İstanbul.

Anonim,2009.www.pseau.org/outils/ouvra ges/acf_gravity_fed_system_in_rural_ar eas_6_hydraulic_ram_pump_systems_2 009.pdf (Erişim Tarihi: 28/12/2019)

Calvert, N G. 1967. Hyraulic Ram, the Engineer.

Krol J. 1951. Automatic Hyraulic Pump. MECHE 1951,184, p. 103

Leonardo Electronic Journal of Practices and Technogies ISSN 1583-1078 Issue 11, July-December 2007, p. 59-70.

Mohammed, S.N., 2007. Design and Construction of a Hyraulic Ram Pump.

Molyreus F., 1960. The Hydraulic Ram for Rival Water Supply, Fluid Hendling, p. 274. 